\title{
Responses of Indigenous People to the Climate Change: A Case Study of the Surels of Dolakha District of Nepal
}

\author{
Hari Prasad Bhattarai*
}

\begin{abstract}
This paper has examined the way the Surels, an indigenous group inhabiting in Suri village of Dolakha district, perceive climate change and also has attempted to document their adaptive strategies to the changes brought about by climate change and global warming. These peoples have developed uniquely insightful ways of observing, interpreting, and responding to the impacts of climate changes through interacting and closely linking their lives with their surroundings. They clearly linked climate change with the changes in the weather patterns over the years indicating erratic rainfall patterns, advancing monsoon, advancing summer and spring, shorter and warmer winter, drier and hotter summer. This paper argues that these people observe and encounter climate and environmental changes immediately and use traditional knowledge and survival skills to adapt to these changes as they occurred. They have devised, though it is not well documented, useful coping mechanisms-modifying cropping pattern and crop types, community-based afforestation and forest management initiatives, improve water management, involvement of community organization in water management and seasonal migration to India- to respond and reduce climate induced risks and impacts which have enabled them to achieve stable livelihoods in their environment.
\end{abstract}

Key Words: Climate change, indigenous peoples, traditional knowledge, anthropology

\section{Introduction}

The climate in Nepal is changing. Temperatures are increasing and rainfall patterns are becoming erratic and less predictable. Largely a hilly and mountainous country, Nepal is ecologically fragile, geologically unstable and environmentally vulnerable and has been highly vulnerable to climate change impacts (Devkota, 2014). The increase in temperatures and shifting of monsoon precipitation patterns in ways will threaten Nepal's current agricultural practices, infrastructure and bio-diversity. These changes are strongly affecting people in many communities - in some cases, threatening their livelihoods and cultural survival (ibid). However, climate change is not a new phenomenon and the people have had long experience with the local manifestations of a changing environment: surging glaciers,

*Mr. Bhattarai is an Associate Professor of Anthropology, Patan Multiple Campus, TU, Nepal 
floods, landslides, forest fires, hazardous and extreme weather, heavy rain and long drought.

Climate change has become a hot issue for the media, academics, politicians and even businesses, as evidence mounts about its scale and seriousness, and the speed at which it is affecting the world. But indigenous groups have been getting very little attentions even though they are among the worst affected. Local and indigenous people in Nepal and elsewhere have reported a wide range of effects of changing climate, from different weather patterns to new and locally-specific ecological phenomena, and the resulting substantial effects on livelihoods and subsistence lifestyles (MoSTE, 2015).

This paper examines the way the Surels, an indigenous people from eastern mountain of Nepal, perceive climate change and their adaptation strategies to climate change. The Surels are the endangered indigenous group of Nepal among 59 Indigenous Nationalities identified by Government of Nepal (GoN). Knowingly or unknowingly they have developed uniquely insightful ways of observing, interpreting, and responding to the array of climate change induced impacts- changes brought due to variation in climatic parameters. Their observations and responses to climate change are therefore of special value in understanding environmental changes, hazards and risks imposed on them by climate change but they have not been documented and analyzed at in detail. This paper aims to fill this gap arguing that these people observe and encounter climate and environmental changes since they are the first to face the direct consequences of climate change due to their high dependence upon and close relationship with natural and environmental resources and use traditional knowledge and survival skills to adapt to these changes as they occurred. It has also attempted to highlight the key coping mechanisms devised to response the various climate change induced risks, hazards and uncertainties. The paper is primarily based on ethnographic interviews conducted with Surel key informants in June-July 2019 and review of literatures.

Compared to other indigenous peoples, including endangered groups of Nepal, there are no or very little published materials or formal written documents available about the Surels. The wider public including academia does not yet know their social, cultural realities, relations of their livelihood to their natural resources or the livelihood strategies, issues of their land, language, customary practices and problems and challenges in relation to their overall development (Bhattachan and Chemjong, 2006). Therefore, there is a lack of comprehensive knowledge about the interrelationship between the Surels their immediate environment in order to know how climate change is affecting these people and how they have been responding to climate change. This article is an attempt to fulfill this gap. 


\section{Climate Change: An Anthropological Perspective}

Climate change is considered to be one of the most serious threats to the indigenous people, with adverse impacts expected on the environment, human health, food security, economic activity, natural resources and physical infrastructure. I have used the term climate change throughout this article to refer to the contemporary phenomenon of anthropogenic global climate change. Anthropogenic global warming results from accumulated human actions that have burned carbon and reduced its sequestration, particularly since the Industrial Revolution. It is thus a result of the '...basic material processes of modern human life' as anthropologist Paul Richards notes, and ' ...dealing with the problem apparently implies the most ambitious plan to reshape human values and existence ever mounted' (Richards 1999, p. 497). Climate change is defined as variation in climatic parameters and is attributed directly or indirectly to human activities (Lange 2005, p. 365). Such variations in climatic parameters occur in addition to or despite natural climate variability ${ }^{10}$. To cope with the consequences of climate change, two approaches are possible: "mitigation" and "adaptation." "Mitigations" are actions taken to limit the degree of future climate change such as reducing carbon dioxide emissions. "Adaptations" are actions taken to adjust to effects of climate change as the climate change is already underway. Adaptation is generally defined as the adjustment in natural or human systems in response to actual or expected climatic stimuli or their effects, which moderates harm or exploits beneficial opportunities (Hardesty, 1977, p. 23-28).

Anthropology's in-depth fieldwork methodology, long engagement in questions of societyenvironment interactions and broad, holistic view of society yields valuable insights into the science, impacts and policy of climate change. Yet the discipline's voice in climate change debates has remained a relatively marginal one until now (Barnes et all 2013). Nevertheless, anthropology offers unique ways to investigate climate change perceptions, understandings and responses and to work with affected communities and interdisciplinary teams. Anthropologists use cultural analysis and theory to understand the diversity of perceptions involving climate change. Climate change is interpreted, explained and lived in local contexts based on local knowledge, culture, political positioning, and the like. From an anthropological perspective, climate change is ultimately about culture, for in its wake, more and more of the intimate human-environment relations, integral to the world's cultural diversity, lose place (Crate, 2011). Anthropologists link the past with the ethnographic present through historical perspectives based on archival research and oral histories.

\footnotetext{
* It indicates changes in climatic conditions that scientists consider to be due to natural mechanisms and processes, and as such are entirely unrelated to human activities (Crate, 2009).
} 
Ethnographic data from across the globe document with increasing frequency the challenges that humans are facing in a changing climate as well as differing interpretations of climate and environments (Bhattarai, 1996). Cultural and linguistic anthropologists investigate climate change beliefs and attitudes, and the religious and ontological questions that climate change provokes (Crate, 2011).

Across all the sub-disciplines, anthropologists have been among the earliest observers to document the drivers of climate change in industrialized nations and less developed states, and the disparate and insidious impacts that climate change is causing. Anthropologists understand how global processes affect local contexts, such as the increasing cash crop production for markets, the search for wage labor and its effects on gender, families and communities, and increasing economic specialization (see Crate and Nuttall 2009). Besides, climate change is a human right and a human security issue. To these ends, anthropological initiatives often work to empower local populations, regions, and nation-states to seek readdress (Wisner et al. 2007, Crate 2008a, Checker, 2009 as cited in Crate, 2011) In this connection, anthropological studies highlight how, on the one hand, global climate change is one more issue that local populations face in the context of contemporary globalization processes and how, on the other hand, it presents novel challenges, especially by rendering what were once suitable survival strategies as obsolete (Crate, 2011).

The peoples in Suri in general and poor and marginalized indigenous people in particular are vulnerable to climate change-induced hazards such as flash flooding, landslides and drought. Such hazards have been occurred more frequently and of higher magnitude in recent years and all have adversely affected community livelihoods. Climate impacts combine with other factors such as a growing human population, the expansion of agriculture onto hill slopes and deforestation have exacerbated flood risks resulting food crisis. These peoples are among the first to face the direct consequences of climate change due to: a) their high dependence upon and close relationship with natural and environmental resources b) their settlements being most commonly located in fragile landscapes and on marginal lands; c) their low position in the power structure, decision making, governance and connectedness, and d) their weak adaptive capacity in the face of new and rapid changes such as those related to climate change (Nakashima, 2012, as citied in MoSTE, 2015 ). Consequently, any changes to the ecosystem may impact on their way of life and survival. This makes them particularly vulnerable to the effects of global warming and also to the impacts of some mitigation measures. Direct and indirect impacts of climate change may threaten their very existence.

As Orlove's work illustrates, understanding climate knowledge requires scientific as well as cultural understandings (Orlove et al 2002, 2008). It suggests that localized scales of 
analysis, which have been the hallmark of anthropology, can complement global modeling exercises that cannot fully capture the complexities of real-life decisions. Community and culture are key dimensions that mediate the interaction between humans and climate. Accordingly, anthropologists are strategically well suited to interpret, facilitate, translate, communicate, advocate, and act both in the field and at home, acting and responding to the causes of change and communities facing and adapting to change (Crate, 2009). Over decades, anthropologists have contributed to our understanding of how societies deal with environmental change and climate variability. Anthropologists are well placed to investigate the role of cultural practices, social contexts and ethical considerations in enabling communities and individuals to respond effectively and humanely to the potentially catastrophic consequences of global climatic changes (Crate 2011; Barnes et all 2013)

\section{Surel's Cultural Ecology and Climate Change}

The Surels are the indigenous peoples of Suri. The Suri VDC lies at the elevation of 13001700 meters in north east from Charikot town, the district headquarter, located about 100 $\mathrm{km}$. east of Kathmandu. The Suri settlement is located in Suri VDC ward No 7 is the traditional homeland of the Surels. Suri VDC and its Suri village cluster in ward number 7 are named after the Suri river that flows from the lower end of the VDC to join the Khare river. Suri settlement was exclusively inhabited by Surels in the past, but now it is inhabited by different castes (Chhetri, Bahun, and Dalits), and indigenous peoples (Surels, and Newars). The total population of Surels in Suri was 157 (52.9\% male and 47.1\% female) in 2006 (Bhattachan and Chemjong, 2006) and VDC record in 2019 shows that the total population of the Surels is 205.

The Surels are mainly subsistence farmers. Non-farming-based wage labor and traditional skills like fishing, mason, and carpentry supplement the farming. Very few Surels are earning their livelihoods by indigenous skill-based occupations like making of bamboo baskets, mats, winnowing tray, strainer etc, honey hunting, bee keeping. Because of the intervention of the modern market system, the development and modernization the indigenous skills such as honey hunting, bee keeping, fishing, bamboo basket making were reported to be gradually disappearing from the village. Those who were making their living by their indigenous skills are heading to crisis in their livelihood.

The Surels are one of the 59 indigenous nationalities recognized and identified by the Government of Nepal. Indigenous people refer to groups whose social, cultural and economic conditions distinguish them from other sections of the national community, who have a special connection with the land and natural environment, and who are often seen as the 'first people' to inhabit a particular territory. Nepal Federation of Indigenous 
Nationalities (NEFIN) classified the Surels as one of the ten endangered indigenous nationalities of Nepal based on indicators relating to literacy rate, housing type, land ownership, occupation, language, population and higher education. However, they are still waiting to be included in the national census. The category "endangered" not only indicates the near extinction of the number of population but also points out to the lowest level of human development.

Surels were the first inhabitants of Suri village (Carter, 2011). It is evident from the fact that all the names of different places, streams, water spring, forest, farms etc. in Suri are in Surel language. For example, there is a small river called Gorangfi (gorang is one of the clan groups of Surel, $f i$ means "to wander") in the lower end of Suri village. The elderly Surels said that the river was given the name because the ancestors of the gorang clan used to wander around the Goranfi river area for hunting and fishing in the past. Similarly, a forest nearby Suri is called Messel (mes means "water buffalo," and sel means "to take bath"). A natural water source in the village is called nebanku (ne means "nose," banku means "leach"). Names of the larger and fertile irrigated lands in the village are in Surel language while the owners are the "high caste" Chhetris. Biru (bi means "cow," ru means "graze") and Ladung's Bhasme (ladung means "name", bhasme means "slash and burn") are the rice farm lands now owned by the "high caste" Chhetris, whose mother tongue is Khas Nepali. Both the names of those irrigated lands are in Surel language. These examples clearly indicate that those lands now owned by Chhetris and other communities belonged to Surels in the past. But they were neither able to compete with others in grabbing of land nor were they able to resist the state's imposition of land and cultural policy against their traditional practices (Bhattachan and Chemjong, 2006).

As the consequences of historical social, political and economic rejection and exclusion the Surels have been pushed to the least fertile and most fragile lands where living conditions are harsh and challenging and where they struggle to survive. As a result of their marginalization and exclusion, these people have very limited access to education, health care, information, technologies, power, resources and national or international aid. With exceptions, they have very limited access to power and decision making. The livelihoods of these peoples are generally dependent on resources that are highly exposed and sensitive to climate variability (e.g. rain-fed agriculture, fragile landscape and dwellings and the absence of a strong social support network) (Bhattarai, 2017). Consequently, they have no choice but to adapt their practices to cope with recurring extreme events and disasters

The ancestral land inhabited by the Surels represents the fundamental element of their cultures and ethnic identity. Land rights, including those pertaining to natural resources, are particularly important for the preservation and development of the identity of the peoples. 
These peoples have managed and shaped their surroundings over centuries, adapting their livelihoods to very specific local natural, physical and climatic conditions. Some particular ancestral territories of the Surels comprise sacred natural sites represented in the form of mountains, rivers, lakes, caves, single trees or forest groves. They are tightly connected to their land, not only through their livelihoods but also through spiritual bonds.

If we study the Surel ways of life, we realize that the historical and mythological connection with nature actually began soon after their inception in this earth. They believe that the gods lived among the Surels during the earliest times. These gods and goddesses, after their time, went to different natural landmarks like nearby peaks, slopes, valleys, ridges, specific sacred trees, to specific sacred rocks, swamps, meadows, pools and streams. Surels consider these landmarks sacred and all the sacred landmarks have been protected and respected by the Surels.

The region where the Surels have been inhabiting is not free from the various geomorphic processes and consequent human security challenges. The most prominent natural challenges that threaten the human security of the region periodically include heavy monsoon rain, flash floods, landslides, soil erosion and other associated natural calamities. The natural environmental challenges are often exacerbated by human induced forces further aggravating the situation. The development interventions particularly construction of road and other local infrastructure without considering environmental issues have at many instances had many negative consequences and impacts on the region.

The disturbing natural processes when coupled with the unplanned development interventions and increasing global warming resulted unintended consequences in the region. The people across the towns and villages narrate revealing insights on how global warming is affecting their lives and livelihood. This is further complemented by the scientific data available. The NCVST (2009) has projected an annual average temperature rise of $1.3^{\circ} \mathrm{C}$ in eastern Nepal by 2030, $1.8^{\circ} \mathrm{C}$ by 2060 and 4.70c by 2090. Analysis of temperature data of Nepalese meteorological stations reveals that there is consistent and continuous warming at an annual rate. In average, the temperature in Nepal is rising by $0.5^{\circ} \mathrm{C}$ per decade (Dahal 2008) which is very high compared to several other developing countries. As result, the rate of change in biodiversity and vegetation pattern in Nepal may increase in double folds due to increasing temperature and deforestation (Kunwar, 2011).

It was observed that climate change affects Surel's wellbeing in two ways, directly through altering local weather conditions inviting extreme weather events and hazards, and indirectly through its effects on ecosystem goods and services that people need for their sustenance. These people are highly dependent on natural resources which they use in many different ways - as food, wood for timber or fuel, fiber for clothing, medicinal plants for 
health care, materials for income generating activities - and depend on for spiritual purposes. Due to the effects of climate change, the availability and distribution of these resources are directly affected resulting an increase of socioeconomic and biophysical vulnerability of these peoples, possibly putting them at risk. For example, the local people reported that increased frequencies of climatic hazards such as droughts and floods have already affected local production negatively leading to frequent crop failure. In addition, it has been reported that the availability and quality of water has decreased causing a loss of biodiversity, which has had fundamental impacts on these peoples' environmental management and livelihoods. For example, due to unavailability of quality water sources, people are forced to use contaminated water for drinking and household as well as for livestock and agriculture putting not only themselves but also their agricultural production at risk.

The loss of biodiversity as a result of potential adverse impacts of climate change have deprived them from important food sources, and reduced their ability to cope with pests and diseases with the help of medicinal plants. For example, the recent climate change in the region resulted in severe economic losses to the beekeeping farmers due to an unusually prolonged dry spell from October 2008 to April 2009. This affected nectar production in plants (due to lack of adequate nectar secretion in the flowers) of the region, which are normally major sources of nectar for bees.

\section{Perceptions on Climate Change}

Communities' perceptions of climate change, of course, vary according to the socioeconomic position of the people, phenomena observed, natural conditions, as well as changes in other factors that might influence their capacity to respond to more or less normal climate variability. Many informants interviewed regarded deforestation as one of the major factors contributing to climate change. Most believed that deforestation, together with rapid and haphazard local road construction and other infrastructure development have added to the air and water pollution, and hence have caused climate change. Rapid increase in human population and the consequent overuse of natural resource have also been regarded as important causes leading to degradation of environment and climate change. Many informants have also linked climate change with the changes in the weather patterns over the years indicating erratic rainfall patterns, advancing monsoon, advancing summer and spring, shorter and warmer winter, drier and hotter summer especially in hilly areas like Suri, Charikot. They also related climate change with the increasing shortage of water for drinking and irrigation. They stated that water resources were gradually drying up and that the amount of water available for drinking and irrigation is diminishing day by day. 
In Suri, for example, most of the farmers feel that the start of the rains has become more unpredictable, as they may come early or late and they are highly localized. Rain is perceived as poorly distributed with torrential rains leading to flooding combined with repeated dry periods in the middle of the wet season and before crop maturity. Peoples observed that earlier, the rain was calm. Now, it is very heavy, like aari ghoptiya jasto (buckets are being emptied) from the skies. And, the heat is very robust. Both conditions are unsuitable for crops. Similarly, snow fall decreased drastically compared to past few decades according to the local people, snow acts as manure for the soil. It melts slowly in the soil and makes it moist and fertile. Now, people experience more wind and heavy rain, which erodes the fertile top soil. All these have led, according to the Surel farmers, to lower production and quality of agricultural products. They observed increase in plant pest and disease attacks at flowering and grain-filling periods and losses of pasture and harvest. They found that the grains are often wrinkled and less tasty.

The general people in Suri have been experiencing changes in the climate in recent decades. They have noted hotter summers and more erratic rainfall accordingly sowing seasons are being changing. Some key informants, however, felt that population growth and heavy human pressure on natural resources, for example, forest degradation, had caused recent disasters alongside intensive rainfall episodes. The informants also reported observing adverse affects on the local ecosystem, and hence on the natural resources on which their livelihood depends, due to changing rainfall patterns and other climate changes.

Surel people said that nowadays garmi (higher temperatures) is increasing in their villages and locality and the changes in temperatures have brought new crops to the villages. Most of the seasonal flowers which were supposed to bloom between March end and early April are already blooming before February end. There are marked evidences of various birds, animals and insects changing their habitation. Amazingly, they are adapting to their new habitations and becoming habitual in the high-altitude regions. Moreover, not only are the animals, birds and insects are changing their habits and habitats, the tree line is also displaying signs of global warming by shifting upward. There are plentiful evidences of the low altitude tree species that are gradually shifting towards high altitude zone as the climate there are becoming hygienic enough for them to

survive. Uttis, a hot climate species, is now abundantly found in high altitude places of Suri. Further, the low altitude trees are being replaced by shrubs like banmara and others kinds of weeds known to invade natural forests rapidly.

NTFPs (Non-Timber Forest Products) have been increasingly recognized to support the resilience and livelihood enhancement of many rural communities including Surels in Dolakha district (Maharjan \& Dangal, 2020). Surel people use NTFPsfor subsistence as 
well as an alternative source of income. Some NTFPs have cultural value and ritual items, whereas, some have medicinal value and contribute to the community's health and wellbeing. Some Surels, who involved in collection of forest products, mentioned that they noticed some impacts on NTFPs due to climate change. They have observed clearly that the stock and distribution of various NTFPs like Guchhichyau (Morchella conica), Khar (Juglans regia), Chiraito (Swertia chirayata), Lauthsalla (Taxus baccata), Satuwa (Paris polyphylla), Kutki (Picrorhiza scrophulariflora) and other herbs in the region are being depleted year to year.

Surel people also relate climate change vulnerability with decreasing crop productivity in the earlier productive and fertile areas, and with the loss of certain cash crops. Farmers have witnessed decreased productivity of millet, paddy, and maize, but increased production of crops such as potato and wheat.

Similarly, community people experience that the flowering and fruiting season of Rhododendron species and Myrica species have been shifted about a month back. The flower and fruit of these species are also a source of income for poor people of the area. Generally, in other season, local people used to go India to earn doing labor intensive work and used to return to house at the time of normal flowering and fruiting season of Rhododendron and Myrica species. As a result of changed season of flowering and fruiting local people did not able to collect them this year.

The key informants' interview reveled that that insects and pests are increasing in recent years. Another aspect of this is that a few species of insects that were common to the area are gradually disappearing, but new species of insects and pests are being observed. One typical example is that mosquitoes were not found in the area in the past but they are severely invading nowadays.

Many new plants that have invasive characteristics are being noticed in the areas in recent years. Hari Bahadur Surel, a local key informant said "I had never seen Banmara (Lantana camara) above 1,500m until a decade ago. However, these days it is found even about $1700 \mathrm{~m}$. Some other new weeds have also emerged.” An interesting fact is that the invasive species are moving gradually to upper elevations, which can be correlated with the warming trend within the area

Some elderly people who had been observing the local environment of the study area shared their experiences about the change in flowering time of plants, giving examples of the seasonal vegetables they had been planting for a long time. The flowering time of some of these vegetables, Cucumis sativus (Cucumber), Luffa cylindrical (Chichinda), Trichosanthes cucumerina (ghiraula), Cucurbita moschata (pumpkin) etc. is changing, i.e. 
it is about a week to up to two weeks earlier than it was twenty or twenty-five years ago. Some Surels also noted that that flowering and fruiting time of Kagati (Citrus limonia) and Naspati (Pyrus calleryana) has also been altered noticeably.

\section{Bhume Puja: A Medium of Perceiving and Responding the Climate Change}

Bhume Puja among the Kiranti People in general and the Surels in Particular is a cultural and religious ritual that establish lively relationship with the surrounding natural environments. The Surels perform Bhume Puja with a wish to bring happiness, progress and prosperity in their life, and with an expectation that the crops flourish, rainfall occurs at the time of cultivation, insect and wild animals give no trouble, crops ripe well, natural disaster and adversity is prevented, shortage of food does not occur etc. They have a strong faith on Bhume and after its worship, crops flourish in their fields, rain falls in time, wild animals do not trouble, diseases do not affect the village, famine does not occur and security prevails. If we take a traditional look at Bhume Puja, it can be taken as a traditional knowledge that is supposed to solve problems related to agriculture. Bhume Puja give us an idea to understand the interrelationship among land, humans (Surels), nature and ancestors. These people used simple agriculture technology and perennial irrigation facility and agri-inputs like improved seeds and fertilizers are far from their reach. They fully depended on the natural environments. In such a situation, people had a belief that whenever any abnormal natural events/incidents used to happen, then it was attributed to the anger demonstrated by God. In such a condition, the practice of worshipping the nature, land was believed to bring good things in life and consequently, this paved the custom of worshipping nature, land and ancestors.

The principle objective to perform Bhume worship (Bhume Puja) is to make the Bhumi Devta (deity) delighted/happy and to worship nature in its essence and also as a respect to ancestors. As nature and the ancestors are the creator of whole human life, the land (nature) is worshipped. Crops that grows on the land (nature) is the cause of existence of human life. Bhume Devta is particularly worshipped during the time of cultivating and harvesting the crops. Bhume Puja is performed with a notion that angry Bhume Devta may prove destructive. Thus, Bhume Puja is performed with a wish to bring happiness, progress and prosperity in their life, and with an expectation of regular rainfall the key factor of good harvest.

In a country like Nepal, where irrigation facility has not been well developed and where people have to depend on monsoon rainfall, the worship of Bhume Devta can help to fulfill their wish at least at psychological level. When rainfall does not occur on time, an agriculturally dependent society will face difficulty in cultivation activities. Hence, there is a belief that Bhume Puja (worship) brings rainfall. Just like, the Newar community worship 
non-human power to get rid of water shortage and worship gods and goddesses to get rainfall. There is a belief that by worshipping an important God Machhindranath can bring rainfall. They worship for the collective well-being. They worship the image (statue) of God Machhindranath, sprinkle water on the statue and also among each other. They believe that by asking water chanting the words 'hara hara Mahadev paani deu', cause rainfall. Surels are also driven by the belief that Bhume Puja (worship) brings rainfall.

The Surels worship the land twice a year; during the full moon day in the month of Baishak (Apr/May) and Mangsir (Nov/Dec). There is a temple/shrine at the foot of a Laankuri tree, (Fraxinus) located near the Surel village, where they gather to worship Bhume Devta (deity). The Naaxo (priest) performs Bhume Puja by asking the deity to help flourish the crops, prevent the attack of insects, bring rainfall during the time of cultivation, prevent natural disaster etc. They have a unique experience that there was rainfall within an hour after the Bhume Puja in the past. Surels say that whenever, drought hits hard in the village, they claim that it might have been so due to the lack of Surel's Bhume Puja and then they suggest to perform Bhume Puja (worship). Moreover, the elderly and senior Surels claim that their Bhumi Devta has power. So, there is a strong belief that worshipping Bhumi Devta can give them power to keep away many agricultures related and other problems.

As Bhume Puja is based on agriculture and the activities related to land and agriculture is displayed during the worship. After the worship (Bhume Puja), dance is performed. The dance includes the acts/mimicry of all agricultural activities ranging from the plantation to harvesting and storing. After the crops get ripen and are ready for harvest, they feel happy as they can survive with food grains and the ancestors and Bhumi Devta are offered gratitude for having given enough food grains that sustain them for a year and making them prosperous and fulfilled. They also ask for forgiveness considering them as the children of the deity with the nature, Bhumi Devta (deity) and the deceased ancestors for any mistakes committed from their side and this happy occasion is marked by singing, dancing and merry making.

\section{Other Strategies of Responding to Climate Changes}

Case studies of social-ecological systems worldwide have yielded four main strategies to cope with change: 1 . learning to live with change \& uncertainty, 2. nurturing diversity for change \& renewal, 3. combining different types of knowledge for learning, 4. creating opportunity for self-organization (Berkes et al. 2003). From the time immemorial, the Surels have observed changes in their environments to predict fluctuations in the weather and climate. Social and communal activities such as feasting, fishing and hunting patterns were planned in response to changes in weather and climate and revolved around the different seasons. As environmental change has already affected their livelihoods in the 
past, in many cases these peoples have developed specific coping strategies to extreme variations of weather. Some examples of such adaptation strategies include:

- Crop diversification in order to minimize the risk of harvest failure (many varieties of crops with differing susceptibilities to droughts, floods, pest etc. are grown). Some of these varieties are adapted to different environment/field locations (near rivers, high on mountains, close to a primary forest etc).

- Change of hunting and gathering periods to adapt to changing animal migration and fruiting periods.

- Change of varieties and species. Crops and livestock varieties have been changed to take account of new disease challenges.

- Changes in food storage methods, such as drying or smoking foods according to climate variability and corresponding availability of food.

- Seasonal Migration

These peoples were also conscious about exploring and assessing indigenous knowledge and technology base in relation to coping strategies, and mentioned that there are already several farming innovations being practiced locally and that the traditional framing systems need technical farming innovations in order to cope with the long-term changes

Some households having risk of flooding during rainy season have changed or improved house structures related to daily life, agriculture and livestock. People have started to build houses on the raised land. Goat pens were also found to be built differently: by raising the height of their stands from the floor so as to protect the goats and sheep from the rise of water level during flooding. Farmers for preserving seeds, grains, cereals and utensils during floods, are also using stilt houses (Thati Ghar).

Building, strengthening, mobilization of community organization to mitigate the climate changes effects is another form of response of climate change. The Surel people visited underlined that the root cause of their vulnerability was closely connected to the lack of organized effort and culture of working together. As a response, they have formed and registered their own community organization called Surel Jati Uthan Samaj (Society for Upliftment of the Surels) which according to them is highly accountable to the community. This also gives the community a legal basis for getting external support and coordinating with other stakeholders within and outside the district. The organization is part of the district and national level organizational networks which will enable it to build links with other institutions and organize resources. They also work hard to resolve local conflicts and have become successful in coming to mutual understanding to use resources in different geographic locations, at least during the disasters. A number of families in Suri have joined hands and decided to collectively initiate preventive measures to reduce climate change induced effects. 
Improving traditional irrigation systems is the other way of responding climate change induced effects. Because of erratic rainfall and extreme weather events, flash floods have been more frequent and of larger magnitude in recent years. Water availability has fallen because groundwater recharge is lower as a result of rainfall being confined to a few days during the monsoon season leaving the rest of the year almost dry. All the household members joined hands to repair irrigation systems damaged by the floods, thus compensating for reduced groundwater availability. Improvements prevented water loss due to seepage.

Temporary migration has been the most viable option for Surels to support their household economy. Migration of Surels to India and elsewhere started in 1950s when a huge landslide occurred in Suri Village. The land slide washed way lands, houses and property of many Surels. Having no other means of survival left in her possession, she left for Darjeeling in search of ways to make her family's living. Since then some Surels followed her and began to go to Darjeeling during the crisis. Some of them never returned to Suri. There are about fifteen Surel families permanently living in Darjeeling calling themselves Mukhiya. This is how even the seasonal migration to Darjeeling from Surel community began and it still continues. Similarly, Purna Bahadur Surel left for Calcutta about the same time the old woman left for Darjeeling. Purna Bahadur's job was a watchman at a slipper factory in Calcutta. Upon his occasional returns to his village and joining back to his job, he also began to take some Surel youths with him to Calcutta. Hence, the seasonal migration to Calcutta began and the Surels have been doing back and forth between Suri and Calcutta for the last 50 years.

The discussions above shed lights on how Surel People of Suri village observe, perceive, and respond to the local effects of global climate change. Susan A. Crate (2011, p. 179) called this sort of research as 'place-based community research'. It provides an important insight that the communities' adaptation to climate variation and change is not a simple function of technical solutions. On the contrary, human adaptation more often is determined by sociocultural relationships manifest in a web of reciprocities, obligations, and assets, including social capital —an asset important for access to resources in times of stress (Crane et al. 2010 as cited in Crate, 2011). These are the "description" of the necessary and context-specific set of tools for surviving and thriving in the local climate change context. These descriptions were collected conducting research over extended periods of time among the Surels through building relations of trust and closely observing people's everyday activities, interactions and conversations, and conducting ethnographic interviews. Through these kinds of encounters and interactions, I have brought to light how these communities - observe changes in the weather, climate and landscapes, and respond to 
these changes. Based on the findings of this study, I fully agree with Barnes et all 2013 who argue that local observations of changes in the climate and local mechanisms developed to deal with those changes can lead to contextualized understandings of climate change impacts and thereby inform adaptation policy.

\section{Conclusions}

The Surels depend on subsistence farming systems, producing crops such as rice, wheat, barley and potatoes. Farming is combined with livestock rearing and these people on high alpine natural resources such as timber, fodder, fuels, fruits, nuts, roots, vegetables and medicinal herbs. These people have their own customary laws, folklore, culture and traditions, which have symbiotic relationships with the local ecological biosphere and conservation. It is generally recognized that poor, natural-resource dependent communities like Surels, are especially vulnerable to the effects of climate change and suffer disproportionate impacts. Ironically, at the same time these peoples are the least responsible for climate change, having the smallest ecological footprint and contributing the least to emissions of greenhouse gases.

It is evident that the Surels are affected by changes in the natural resource based on which they fully depend as a consequence of climate change. Moreover, the effects are likely to be intensified in the future as continued climate change is predicted to lead to major changes in freshwater flows, with dramatic impacts on biodiversity, people and their livelihoods. Indigenous peoples in general and the Surels in particular have been observing the melting of ice and glaciers, and environmental changes in their traditional territories for many years. Although they are not familiar with scientific data on climate change, they are experiencing the disappearance of foods, medicinal plants and herbs and they feel certain that the changing climate is the reason for the changes they are experiencing in their daily interactions with the local environment.

In response, Surels innovate with cropping system, modify the dwelling environment and diversify their livelihoods to adapt to the prevailing climatic and non-climatic stresses. All these efforts have helped them to build resilience in the face of recurrent disasters. Crop diversification in order to minimize the risk of harvest failure, change of hunting and gathering periods to adapt to changing animal migration and fruiting periods, change of varieties and species, improve water management, formation of community organization, changes in food storage methods and seasonal migration are some responses of the Surels to reduce climate change induced risks and impacts.

\section{Bibliography}

Battersbury, Simon (2008). Anthropology and Global Warming: The Need for Environmental Engagement. Australian Journal of Anthropology, 19 (1)

Bhattachan, K.B and Chemjong D. (2006). Achieving the Millennium Development Goals among the Indigenous Surels of Nepal, A Report Submitted to International Labor Organization (ILO)

Bhattarai, H.P. (1996). The Rajbanshis of Rajgadh: Community Adaptation in the Environment of Eastern Tarai. Occasional Papers in Sociology and Anthropology. Kritpur: Central Department of Sociology and Anthropology, TU 
Bhattarai, H.P. (2017). Indigenous Peoples and Right to Natural Resources: An Assessment of Changing Paradigms of Forest Tenure Rights in Nepal. Journal of Development Innovations, 1 (2): $29-57$

Barnes, J. et all (2013). Contribution of anthropology to the study of climate change. Nature Climate Change, Vol 3. Available: www.nature.com/natureclimatechange

Berkes F, Colding J, Folke C. eds. (2003). Navigating social-ecological systems: building resilience for complexity and change. Cambridge: Cambridge University Press.

Carter, Jane (2011). Surikokura: Development and social change in a Nepali village. A book available at http://surikokura.org.

Crate S, Nuttall M, eds. (2009). Anthropology and Climate Change: From Encounters to Actions. Walnut Creek, CA: Left Coast Press

Crate, S. (2011). Annul Review of Anthropology, 40:175-94

Crate S. (2008). Gone the bull of winter: grappling with the cultural implications of and anthropology's role(s) in global climate change. Current Anthropology, 49(4):359-95

Dahal N. (2008). Understanding climate change adaptation issues in Nepal. The Initiation, 2: 138144.

Devkota, R. P. (2014). Climate change: trends and people's perception in Nepal. Journal of Environmental Protection, 5:255-265.

Hardesty, D. L. (1977). Ecological Anthropology. New York: John Wiley \&Son

Kunwar, R. M. (2011). Assessment of Climate Change Impacts on Non-Timber Forest Products (NTFPs), Medicinal and Aromatic Plants (MAPs) and Important Tree Species (ITS) in the Sacred Himalayan Landscape, Nepal: A Report submitted to WWF Nepal Program, Baluwatar, Kathmandu. Available: https://www.researchgate.net/publication/262011539_Climate_Channge_Impacts_on_NTFPs/li nk/00b7d5365bce007644000000/download

Lange, M. A. (2005). Climate change. In Mark Nuttall (Ed.), Encyclopedia of the Arctic, 365-73. New York and London: Routledge.

Maharjan, S., \& Dangal, M. R. (2020). Economic Contribution of Non-Timber Forest Products in Rural Livelihood of Dolakha, Nepal. Open Journal for Research in Economics, 3(2).

MoSTE (2015). Indigenous and Local Knowledge and Practices for Climate Resilience in Nepal, Mainstreaming Climate Change Risk Management in Development. Kathmandu: Ministry of Science, Technology and Environment (MoSTE), Nepal.

NCVST (2009). Vulnerability through the eyes of vulnerable: Climate change induced uncertainties and Nepal's development predicaments. Kathmandu and Boulder, Colorado: Institute for Social and Environmental transition-Nepal (ISET-Nepal) and Institute for Social and Environmental Transition (ISET) for Nepal Climate Vulnerability Study Team (NCVST)

Orlove, B., Wiegandt, E., Luckman, B. H, (2008). The place of glaciers in natural and cultural landscapes. In Orlove, B., Wiegandt, E., Luckman, B. H, (Ed.), Darkening peaks: glacial retreat, science and society (pp. 3-19). Berkeley: University of California Press.

Orlove, B., Chiang, J., Cane, M. (2002). Ethnoclimatology in the Andes: A cross-disciplinary study uncovers a scientific basis for the scheme Andean potato farmers traditionally use to predict the coming rains. American Scientist, 90 (5): 428-435.

Richards, P (1999). Review of S. Rayner and E. Malone. (eds), Human Choice and Climate Change (4 volume). GeoJournal, 47 (3): 497-498 